\title{
Referral letters to the psychiatrist in Nigeria: is communication adequate?
}

\author{
Oluyomi Esan ${ }^{1}$, Oluremi Oladele ${ }^{2}$
}

1. Department of Psychiatry, University of Ibadan, University College Hospital, PMB 5116, Ibadan, Nigeria. Telephone: +234 8033880312; E-mail: oluyomie@yahoo.com

2. Department of Psychiatry, University College Hospital, PMB 5116, Ibadan, Nigeria. Email: oluremi_oladele@ yahoo.com Telephone number: +2348034974959

\begin{abstract}
Objective: Over half of patients with psychiatric disorders are first seen by primary care physicians before referral to the psychiatrist. An efficient referral system is, therefore, important to offering quality care to such patients. Communication between physicians is often sub-optimal and referral letters to specialists sometimes provide inadequate information. The current study's aim was to observe the prevalence of deficiencies in the referral letters to a department of psychiatry in a Nigerian teaching hospital. Methods: All referral letters to the Department of Psychiatry, University College Hospital Ibadan, Nigeria over a three- year period from January 1, 2010, to December 31, 2012, were retrieved and assessed for quality using the Consultation and Referral Request Letter Assessment Tool.

Result: A majority ( $>80 \%$ ) of the referral letters had no information on the current medication list, relevant psychosocial history, outline of management to date, results of investigations to date, and known allergies.

Conclusion: Deficits in communication or information transfer through referral letters to the psychiatrist are common. Interventions such as the use of standardized formats for such letters may facilitate more efficient communication.
\end{abstract}

Keywords: Communication; Letter; Nigeria; Psychiatrist; Referrals.

DOI: http://dx.doi.org/10.4314/ahs.v16i4.19

Cite as: Oluyomi E, Oluremi O. Referral letters to the psychiatrist in Nigeria: Is communication adequate? Afri Health Sci2016;16(4): 10231026. http://dx.doi.org/10.4314/ahs.v16i4.19

Background: Psychiatric disorders contribute significantly to the total global burden of diseases ${ }^{1}$. Over half of patients with psychiatric disorders are first seen by primary care physicians before being referred to the psychiatrist. The reasons for referral include a doubtful diagnosis, poor results from treatment and emergency situations $^{2}$. An efficient referral system is therefore not only important to offering quality care to such patients and their relatives, but also to the society by saving unnecessary waste of time and avoidable expenditure. Quality communication is crucial to a safe and efficient referral process. Furthermore, the referral process is a critical component of quality clinical care. An efficient referral system is a two-way process that involves the transfer of
Corresponding author:
Oluyomi Esan,
Department of Psychiatry,
University of Ibadan,
University College Hospital,
PMB 5116, Ibadan, Nigeria.
Telephone: +234 8033880312;
E-mail: oluyomie@yahoo.com

relevant clinical information from the referring physician (e.g. primary care physician) to another physician (e.g. specialist) and vice versa.

Vehicles for referrals take many forms (letters, telephone, e-mail, on-line link etc.) depending on the culture and geographic location. For example in many African and European countries, referral letters are the primary means of communication between primary care physicians and specialists whereas in the USA a phone referral may be more prevalent. It is crucial for a referring physician working in sub-Saharan Africa to know what information the referral letter should contain, since the literacy rate in the region is very low and patients may not be educated enough to inform doctors to whom they are referred about pertinent information such as medical illnesses they are being treated for or the medications they have been placed on.

Apart from information transfer, referral letters also serve as a means of educating physicians. The psychiatrist, for example, can serve as a teacher and consultant to the primary care physician since such a psychiatrist 
deals with serious mental and emotional problems that are beyond the skills of the primary care physician ${ }^{3}$. Collapse in communication through a poor referral system can lead to poor continuity of care, repetition of investigations, increasing poly-pharmacy, delayed diagnoses, increased health care costs and decreased quality of care ${ }^{4}$. 5. Communication between the referring physicians and other physicians is often sub-optimal and referral letters to specialists sometimes provide inadequate amount of information ${ }^{6-8}$. It is not uncommon to get referrals with missing reports of previous investigations, insufficient detail in the referral letter, absence of an explanation for the referral or statements such as "the above named is a known psychiatric patient $\mathrm{He} / \mathrm{She}$ is being referred to you or "Mr. X has been behaving abnormally $\mathrm{He} /$ she is being referred to you ".

Even though proficiency in written communication is essential to the practice of physicians, most physicians do not receive any training in the art of writing referral letters9. Communication among physicians can always be improved upon and an excellent way to start is by measuring its deficiencies. Few studies have investigated the information content of doctors' letters, especially in sub-Saharan Africa. The current study's aim was to investigate the quality of referral letters to a department of psychiatry in a Nigerian teaching hospital.

\section{Methods}

This study was conducted at the University College Hospital (UCH), Ibadan Nigeria. UCH is an academic tertiary care teaching hospital and referral centre located in Ibadan, Southwest Nigeria. The estimated population of South West Nigeria is about 28 million 10. The hospital receives referrals specifically from health facilities in the South West geopolitical zone of Nigeria and frequently from all geopolitical zones of the country.

All referral letters to the Department of Psychiatry, University College Hospital Ibadan, Nigeria over a three-year period from January 1, 2010, to December 31, 2012, were retrieved from their case notes and assessed for quality using the Consultation and Referral Request Letter Assessment $\mathrm{Tool}^{11}$.The tool has 18 items that assesses content , style and overall appreciation of referral letters. The 18 items are divided into 15 content and 3 style items. It also includes a 5- point Likert scale to provide an overall rating for each referral letter. The current study only assessed the content of the letters. Data extracted included patient demographics, initial statement identifying the reason for the referral, past medical history, past surgical history, relevant psychosocial history, current medication list, allergies, relevant clinical findings, results of investigations to date, outline of management to date, provisional diagnosis or clinical impression, and a statement of what was expected from the referral.

\section{Results}

There were 284 referrals to the Department during this period. Over half,(58.1\%) of the referrals came from the general out-patient department (i.e. referrals from the primary care physicians) $23.6 \%$ of the referrals came from other hospitals Table 1.

\section{Content of Referral Letters}

A majority, $(>80 \%)$, of the referral letters had no information on the current medication list, relevant psychosocial history, outline of management to date, results of investigations to date, allergies and an initial statement identifying the reason for the referral. However, most $(>60 \%)$ of the referral letters had information on patient demographics, description of chief complaint and a statement of what was expected from the referral letters (Table 2)

\section{Discussion}

The evidence presented indicates that the referral letters to the psychiatrist provided inadequate amount of information for patient care. Analysis showed that the letters accomplished the basic objective of transferring some clinical and administrative information such as Initial statement identifying the reason for the referral, patient demographics, description of the chief complaint, provisional diagnosis, and statement of what is expected from the referral. However they were less likely to contain items such as a description of relevant collateral history, the past medical history, relevant clinical findings, the current medication list, relevant psychosocial history, outline of management to date, results of investigations to date, allergies, and past surgical history. The results in the current study are similar to findings in some studies from other climes. For example in the study by Newton 
et al (1994), 95\% of the referral letters indicated the reason for referral while we found $94.4 \%$. Similarly, relevant psychosocial history was only mentioned in $11.9 \%$ of the referrals compared with $18 \%$ by Newton et al ${ }^{12}$. Also, our study showed that $20 \%$ of the referrals indicated the relevant medical history. This is lower than the $29-62 \%$ that has been previously reported ${ }^{12-14}$. Unlike the study by Newton et al where only $5 \%$ of the referrals indicated a statement of what was expected from the referral, about $70 \%$ of the referrals in the current study indicated a statement of what was expected from the referral ${ }^{12}$.

It is noteworthy that in $2.5 \%$ of the referrals, the source of referral was not indicated. This suggests that such patients were probably not attended to, since the source of referral is usually necessary to locate a patient in need of such psychiatric evaluation or treatment.

If it is accepted that improvement in communication between the referring physician and the psychiatrist is desirable, then it is necessary to consider how to rectify the deficiencies indicated in the current study. An effective way to enhance information content and communication in referral letters to specialists is the use of form letters. ${ }^{15-17}$ Form letters are letters written from templates, rather than being specially composed for specific recipients. They contain more information than non-form letters ${ }^{17}$ and have been shown to improve the quality of referral letters ${ }^{18}$. In addition, physicians prefer to receive such letters as referrals ${ }^{15}$. In addition, because such letters use laid out titles, it allows the reader to easily identify the information desired, thus saving time for both reader and writer.

Another way in which communication using referral letters can be enhanced is for physicians to get trained in the art of referral letter writing. Attending letter-writing training courses can significantly improve the content of referral letters of doctors. Conducting a letter-writing course may, however, be an expensive intervention? ${ }^{7}$. It may also be beneficial for such letter-writing courses to be introduced to the medical curriculum both at the undergraduate and postgraduate levels.

Even though our study was conducted in one specialty (psychiatry), it is unlikely that the referral letters to other specialties would be different from what has been observed in the present study.

One limitation of this study is that it was done at a sin- gle large tertiary care teaching and referral centre. The problems faced by physicians at this site may be different from the challenges at smaller institutions. Furthermore, we did not look at the designation of the writers of the referrals. It would have been beneficial to segregate the letters into the different cadres of doctors in the teaching hospital (i.e. specialist/ consultants, residents, medical officers, house officers).

However, often times in clinical practice consultants seldom write referrals. The younger colleagues in the team are usually saddled with that responsibility. It is however of strategic importance to mandate senior residents to cross check outgoing referrals on behalf of their consultants. Again, we described the deficiencies using a tool that was developed for use within a family medicine practice. This may not reflect informational elements that may be of more relevance to psychiatrists when receiving referrals. It would be beneficial to have a group of psychiatrists establish a checklist of items that they find particularly important for their practice as a tool for assessing the adequacy of the information contained in referral letters. For example, some of the missing elements that were discovered through this study, such as psychosocial history, may not be elements that non-psychiatrist physicians routinely collect during their examinations and, therefore, one would not expect such information to be available to be included in referral letters.

\section{Conclusion}

Deficits in communication or information transfer through referral letters to the psychiatrist are common. Interventions such as the use of standardized formats for such letters may facilitate a more efficient communication.

\section{Conflict of interest}

None to declare.

\section{References}

1. Prince M, Patel V, Saxena S, Maj M, Maselko J, Phillips MR, Rahman A. No health without mental health. Lancet. 2007;370(9590): 859-77. DOI:http://dx.doi. org/10.1016/S0140-6736(07)61238-0

2. Shilling $\mathrm{KH}$, Bass RL.Use of adult psychiatric services by primary care physicians in midwestern cities. Nebr Med J. 1990;75(3): 37 -42.

3. FinkPJ. Psychiatry and the primary care physician. Hosp 
Community Psychiatry. 1985;36(8): 870-5. http://dx.doi. org/10.1176/ps.36.8.870

4. Epstein RM. Communication between primary care physicians and consultants. Arch Fam Med. 1995;4(5): 4039 .

5. Kripalani S, LeFevre F, Phillips CO, Williams MV, Basaviah P, Baker DW. Deficits in communication and information transfer between hospital-based and primary care physicians: implications for patient safety and continuity of care. JAMA. 2007; 297(8):831 -41.

6. McGlade KJ1, Bradley T, Murphy GJ, Lundy GP. Referrals to hospital by general practitioners: a study of compliance and communication. BMJ. 1988; 297(6658):1246 $-8$.

7. Tattersall MH, Butow PN, Brown JE, Thompson JF. Improving doctors' letters. Med J Aust. 2002; 77 (9): 51620.

8. Tattersall MH, Griffin A, Dunn SM, Monaghan $\mathrm{H}$, Scatchard K, Butow PN. Writing to referring doctors after a new patient consultation. What is wanted and what was contained in letters from one medical oncologist? Aust N Z J Med, 1995; 25(5):479 -82. doi/10.1111/j.1445-5994.1995.tb01491.x/pdf

9. LingardL, Hodges B, MacRae H, Freeman R. Expert and trainee determinations of rhetorical relevance in referral and consultation letters. Med Educ, 2004; 38(2): 168 -76. DOI: 10.1111/j.1365-2923.2004.01745.x
10. National Population Commission Nigeria, National Census. 2006.

11. François J. Tool to assess the quality of consultation and referral request letters in family medicine. Can Fam Pbysician. 2011; 57(5): 574 -5.

12. Newton J, Hutchinson A, Hayes V, McColl E, Mackee I, Holland C. Do clinicians tell each other enough? An analysis of referral communications in two specialties. Fam Pract. 1994; 11(1): 15 -20.

13. Hansen JP, Brown SE, Sullivan RJ Jr, Muhlbaier LH. Factors related to an effective referral and consultation process. J Fam Pract. 1982; 15(4): 651 -6.

14. Graham PH. Improving communication with specialists. The case of an oncology clinic. Med J Aust. 1994; 160(10): $625-7$.

15. Lloyd BW, Barnett P. Use of problem lists in letters between hospital doctors andgeneral practitioners. BMJ. 1993;306(6872): 247

16. Rawal J, Barnett P, Lloyd BW. Use of structured letters to improve communication between hospital doctors and general practitioners. BMJ; 1993;307(6911):1044 .

17. Jenkins S, Arroll B, Hawken S, Nicholson R. Referral letters: are form letters better? Br J Gen Pract. 1997; 47(415): $107-8$.

18. Couper ID, Henbest RJ. The quality and relationship of referral and reply letters. The effect of introducing a pro forma letter. S Afr Med J. 1996; 86(12):1540 -2. 